\title{
LAS VERDADES DEL CUERPO CARTESIANO
}

\author{
Félix Duque \\ (Universidad Autónoma de Madrid)
}

Desde el Juan de Mairena machadiano, todos nosotros dudamos de que sea verdad la supuesta afirmación del Atrida, según la cual "la verdad es la verdad, digala Agamenón o su porquero", aleccionados como estamos por el atrevimiento del pobre porquero que, al menos por una vez en su vida, se atreverá a matizar la universalidad del real aserto para introducir un cauteloso: "Eso depende". Si nosotros fuéramos cartesianos ( $y$ de algún modo lo somos, al igual que somos velis nolis griegos y cristianos), diriamos que "eso" depende, entre otras muchas cosas, de que el cuerpo del porquero esté igual de bien conformado y equilibrado que el de su poderoso señor. Bien podemos conceder, en efecto, que: "La vérité consiste en l'être", I mientras no entremos demasiado en las entretelas de tan escurridizo término como el de "ser». Pero algunos nos sentíriamos más inquietos si tuviéramos que asentir igualmente a un aserto cartesiano mucho más preciso, a saber: "omnia quae clare cognosco esse vera". 2 Aqui no sólo se ha precisado ya el ser como "ser-para-el-conocimiento-claro", sino que implicitamente, a través de la terminación verbal, se ha deslizado una particula: ego, que dará mucho que pensar, sobre todo si entendemos su referente como resultado de un proceso absoluto de abstracción y reducción en el que todo contenido parece haberse evaporado, hasta que sólo queda en nuestras manos el acto purísimo de pensar: la acción solitaria, la soledad del agente que parece habérselas tan sólo consigo mismo. Contra tal reduccionismo, a la memoria acuden los versos de Macliado: "En mi soledad / he visto cosas muy claras, / que no son verdad".

Pero claro está que el buen caballero Descartes nunca estuvo del todo a solas (o dicho retóricamente: ese "yo" por él proferido no dejó nunca de ser, ni aun para él mismo, una catacresis, el tropo o la figura del abuso). Hacia "fuera", por decirlo de una manera imprecisa (pero menos deformante que si habláramos de "espacio"), Descartes se encontró - como todos nosotros- rodeado de cuerpos que, en lugar de estarse quietos en su lugar, esperando a ser captados en su realitas objectiva por la penetrante acies mentis del filósofo, lo asaltaban en tropel, a la vez que se inmiscuian unos en otros, eran engullidos o aplastados unos por otros o se alejaban entre si. De la otra parte, hacia "dentro" - si queremos- la cosa no parecia ir en absoluto mejor: no sólo el propio cuerpo cartesiano se veia obligado a engullir otros cucrpos y a expulsar los desechos, a la vez que evitaba en lo posible ser traspasado, aplastado o engullido por los cuerpos "exteriores". Y más hacia "dentro" aún, en el hondón de la conciencia -alli donde cabria esperar algo asi como un trasunto interiorizado del topos hyperouraniós platónico, lleno de verdades-estatua, de ideas bien dispuestas a la captación reflexiva-, se encontraba una extraira Verdad, inteligible sólo por vía negativa, como imposible Polo desde el que comprender nuestra poquedad y finitud, nuestro sabernos enganados a cada instante: una sustancia, o mejor: la sustancia por antonomasia, definida también ella negativamente como lo que no necesita de otra cosa para existir (lo cual implica que el mismo Descartes si que necesitaba - como todos nosotros - de muchas cosas para existir). Se trataba obviamente de la "sustancia” Dios: una identidad perfecta en la que coinciden Ia immensa potestas (la capacidad suma de medir sin ser medido) y la Naluraleza, entendida como absoluta posición de medida, dentro

I Carta a Clerselier de 23 de abril de 1649: A.T. V, 356.

2 Meditaniones de prima philosophia [Med.] V. A.T. VII, 65. 
de la cual todo alcanza peso y lugar. En el Dios cartesiano coinciden pues lo Mensurante y la coordinatio de toda medida posible: el Ser indeterminado y omnideterminante que permite toda determinación, el impensable Pensamiento que posibilita todo pensamiento. ${ }^{3}$

Todos conocemos la gigantesca operación de orden llevada a cabo por Descartes para encontrar un lugar firme e inquebrantable en medio de tanto tropel y hasta de tropelias. Ese lugar es el de la medida que se da la medida a si misma, de manera refleja, exactamente equidistante de la avasalladora pululación de lo exterior, sin orden ni concierto aparentes, y la no menos amenazante puntualidad de un Ser absolutamente in-diferente: pura puntualidad eterna. Podemos decirlo de manera muy concisa: contra la experiencia griega del saber humano como aprendizaje a través del padecimiento y después de éste, expresado en las duras palabras de Esquilo: páthei máthos, se trata de encontrar el camino, el méthodos por el cual lo Uno y lo múltiple resulten coordinados a cada instante, puntualmente. Se trata en suma de hacer de la experiencia sentida, padecida, algo cognoscible, esto es: anticipable y previsible, al menos en cuanto a la forma. El subjectum griego —ejemplificado a la perfección en Aristóteles-era el ámbito en el que combatian sin tregua, literalmente a muerte, por un lado la scintilla divinitatis, el nouts poietikós, separado y sin embargo presente a la psyché: el agente en fin del conocimiento, y por otro el notis pathetikós, receptivo a la verdad de lo ente a través de la phantasia, cl receptáculo quodammodo de todas las cosas: el sujeto de experiencia. El caballero que, según Péguy, "dio tan buen paso" anudó en realidad la fractura griega entre experiencia y conocimiento: el sujeto cartesiano no va en efecto a ningún sitio, no sale de si. Él es la conexión puntual, a cada instante, de experiencia y de conocimiento. No es en realidad un paso, sino un punto. Un punto arquimédico desde el cual el mundo es puesto en su sitio verdadero, sacándolo de las casillas de la ilusión de una amenaza externa: "Nihil nisi punctum petebat Archimedes, quod esset firmum \& immobile, ut integram terram loco dimoveret". 4

¿En qué consistia la amenaza, expresada turbadoramente por los griegos en el monumento funerario de la tragedia? Esta amenaza consistia en que las cosas (incluyendo en ellas a los dioses) estaban separadas del individuo judicativo, que sólo podia llegar a ellas demasiado tarde, tras sentir el favor o la hostilidad de lo ente. Todas las cosas se hundian en el secreto de la heimarméne, de la moira, incognoscible aun para si misma. Y ya es interesante señalar que "secreto", secretus, significa "separado", "apartado" (del verbo secernere). Para Descartes (y con èl, para toda la Modernidad) nada debe haber en cambio secreto, separado: todo debe estar al alcance de la bona mens, de ese "sentido" con que se abre el Discurso del método: "la cliose du monde la micux partagée". ¿De qué puedo estar cierto? No desde luego de una acción pura y creadora (ella misma seria entonces "secreta", estaría soberanamente apartada), ni tampoco de una pasión, de un páthema al que seguiria, tentativamente, el conocimiento, sino sólo del hecho extraño - por evidente- de que no existe en general la verdad o el engaño, es decir: que lo que existe es el hecho de que yo estoy en la verdad o bien me engaño. Entre el páthema y el máthema media el enlace circular: la refexión del ego cogito. Y esa reflexión es lingiiissica. Después de haber dudado de todo, aun de un pensamiento claro y distinto llevado al engaño por un genio maligno, Descartes concluye: "denique statuendum sit hoc pronuntiatum, Ego sum. ego existo, quoties a me profertur, vel mente concipitur, necessario esse verum." ${ }^{\text {Adviértase }}$

3 Aled. VI; A.T. VII, 80: "per naturam enim, generaliter spectatam, nihil nunc aliud quam vel Deum ipsum, $\mathrm{vel}$ rerum creatarum coordinationem a Deo institutam intelligo".

4 Med. II; A.T. VII, 24.

5 Mled. II; A.T. VII, 25. (Negritas mias). 
desde luego que se trata de una proferencia, de una enunciación en la que - como recuerdo laico del acto cúltico de la Eucaristia-la palabra y la cosa coinciden; más aún, la palabra refleja, que vuelve a si desde el engano (exterior o interior) es la concepcion, en todos los sentidos de la palabra, de la verdad.

Literalmente, no puedo saber verdad alguna - para empezar, de mi mismo- si yo no la pronuncio $y$, a través de ella, me pronuncio. En esa enunciación se detiene el tiempo, es decir: el constante desequilibrio entre experiencia y conocimiento. Cuando yo la pronuncio, cuando "yo" se pronuncia, en la raiz misma del lenguaje, alli donde verbo y carne coinciden, el liombre moderno queda absuelto de la vida, como si ya estuviese muerto para el mundo: "Ego sum, ego existo; certum est. Quandiu autem? Nempe quandiu cogito; nam forte etiam fieri posset, si cessarem ab onmi cogitatione, ut illico totus esse desinerem."6 Es obvio que, para Descartes, es imposible no pensar en nada. Sólo que no reflexionamos sobre ello. Pero no menos obvia es la dificultad de pensar en la acción misma de pensar, puramente, haciendo abstracción de todo contenido, de toda incitación y determinación: algo tan dificil, que Descartes se contenta con que lo intentemos al menos una vez en la vida. El alma cartesiana es sempiterna (no cterna, pues que se recoge a sí misma sólo desde el error); sólo que casi nunca lo sabe. Sólo tiene conciencia de ello en un instante, un extraño instante de reflexión: cuando adecúa su verbum interius (lo que ella, de siempre, es: su esencia) con su verbum prolatum (su decirse lo que ella es: su existencia).

¿Qué dice el cogito de si mismo? Sólo esto: ego sumt pro-nomen, la anticipación formal de cualquier nombre, de toda dicción con sentido, sin sustancia alguna. Habria mucho que hablar de la hipóstasis cartesiana del "Yo", enseguida notada por Arnauld y por Hobbes. La terminologia escolástica que Descartes toma de prestado disfraza la radicalidad de su propuesta. En verdad, el ego cogito no puede ser una res, puesto que de ella nada se dice: no es cosa real $y$, por ende, sólo dice el acto de su vacuo decir. Ni tampoco es una substantia, pues que nada le pasa ni nada hace de por sí y en sí: vive de indirectas. Justamente, como un complemento indirecto. Consiste en hacer que las cosas sean hacederas, decibles y cognoscibles. Por eso se expresa a sí misma como un puro participio de presente, entre el orondo infinitivo del Ser y la pura pasividad de la máquina cósmica: "Ego sum res cogitans, id est dubitans, allirmans, negans, pauca intelligens, multa ignorans, volens, nolens, imaginans etiam \& sentiens."7 Adviértase que, de este modo, el cogito participa en la presencia, sin estar jamás entera y plenamente presente a si mismo, sin ser idéntico a sí, ni tampoco diferente de si. Pura suspensión entre lo Uno y lo Múltiple, cortadura o barra entre la Identidad y la Diferencia, el ser y el devenir ¿qué puede hacer el punto arquimédico del cogito, sino tomar las medidas de la realidad al medirse con ella? Entre el Dios que todo to ve y las cosas que están alí para ser vistas, Descartes introduce una astucia humana: un artificio o industria -como el Basilio del Quijote. que gritaba a la gente estupelacta: “¡No milagro, milagro, sino industria, industria!”- - No es extraño que uno de nuestros filósofos guste de lablar de las Industrias Cartesio.

Sólo que toda industria necesita de materias primas a las que refinar. $Y$ el primer funcionamiento de la máquina Descartes consiste en reducir el Mundo a Máquina, con la secreta intención de lograr un perpetumm mobile, una ecuación plena entre input y output. Que la industria le salio relativamente bien con los llamados "cuerpos exteriores" lo prueba sin más nuestro mundo industrializado e informatizado: todo - hasta la politica y la diversión- la de

6 Med. II; A.T. VII, 27.

7 Mled.. III; A.T, Vit, 34. 
ser público, sin secretos, hasta convertirse en la livida brillantez de los puntos fotónicos de las pantallas, reconvertidos por cada espectador en imagen virtual. $Y$ conocemos muy bien el paradigma de esta operación: se trata de reducir toda diversidad cualitativa, toda determinación de suyo, a orden y medida, desde la homogeneidad presupuesta. La materia inerte, sin desgaste ni auge reales, esto es: sin tiempo propio, sin desequilibrios de principio entre lo susceptible de ser sentido, experimentado, y lo cognoscible, o sea lo susceptible de anticipación teórica, viene expresada mediante un participio de pasado (pues que la totalidad del tiempo, o sea el entero tiempo ya sido, muerto como la vis mortua generadora de apariencias, equivale al espacio). La materia es res extensa, puro hundimiento en un pasado ya siempre sido, elevado a presencia sólo a través de la ciencia de la experiencia de la conciencia (que no en vano la Fenomenologia hegeliana dice, ya desde su titulo primitivo, la verdad implicita en el programa cartesiano). La experiencia en que se da el conocimiento ( $y$ al mismo tiempo, en circularidad reflexiva, el conocimiento que hace la experiencia): en suma, la conversión de todo posible páthema en máthema viene narrada en las Meditationes en un pasaje clamorosamente célebre: el del morceau de cire.

Descartes comienza por las cosas que el vulgo cree entender distinctissime. ${ }^{8}$ El camino -n lejano homenaje al proceder aristotélico en fisica y a la vez como claro anuncio del método hegeliano- irá de lo más distinto para la gente, pero más confuso en verdad, katá plyysin, a lo más confuso para la gente ( $\mathrm{y}$ en efecto, nada en apariencia más confuso que una masa fundida) pero más distinto en si, o sea para nosotros, los filosofos. Descartes clige como objeto ejemplar hanc ceram. "Esta cera": una cosa individual, como el tode ti. El camino consiste en una verdadera separatio a sensibus e sensibilibus: una ablación y hasta, si se quiere, un desollamiento de la piel en la que se confunden subjetividad y objetividad. El experintentum crucis es una purificación tanto de las supuestas cualidades de las cosas como del sentimiento subjetivo de éstas: lo que restará no será ni una acción ni una pasión, sino una pura pasividad ni siquiera exterior (puesto que ella: la cera, no se exterioriza ni manifiesta), sino simplemente externa: al "yo" y a si misma. Pura superficie: grado cero de la realidad. De ella nos resta un resto, un cadáver.

Recordando al poeta que una vez quiso ser, Descartes comienza su industrioso experimento con una alusión a la colmena de la que se extrajo la cera (una alusión, pues, a su presunto "lugar natural", al sitio a que ella se debe y del que tenemos experiencia). En seguida se nos habla de las relaciones que tenía con otro cuerpo: la miel, asi como - casi silogisticamente-con la procedencia de ésta: la flor. Pero esas relaciones están mediadas por la sensación que de ellas tenemos: sabor y olor. Sensaciones debidas empero a un solo sentido y, por cnde, no susceptibles de comparación ni de publicidad: sensaciones ellas mismas secretadas y secretas, separadas, tanto del cuepo de referencia como de comprobación comunicable a otros hombres. Luego, a través del color (por el que la cosa se liace pública para la mayoría de los hombres), llegamos a sensaciones correspondientes a eso que la tradición llamará cualidades primeras: figura, magnitudo, y que son manifiestas, comunicables para todos los hombres sin excepción, por ser a la vez visibles y reductibles al tacto. Y en efecto, se nos dice al punto de la cera que es dura, frigida. facile tangitur. Al final, lo más importante: si articulo ferias, emittet somum. Tiene pues un "interior" que vibra al ser golpeado, herido, como un remedo del lenguaje animal y humano. Es como si haec cera pudiera, a su vez, "sentir", como

8 Para lo que sigue, véase la Med. II; A.T. Vil, 30-31. 
un grotesco simulacro del ser vivo. No delante del hombre, como un objeto separado, sino en la frontera móvil del hombre, en los sentidos, se abre pues la cosa y sus cualidades.

Pero ahora comienza el experimento: una verdadera tortura por la cual la cosa dirá su verdad, oculta tras las proteicas apariencias. $Y$ aqui, de nuevo, se da la conjunción de industria y lenguaje: "Sed ecce, dum loquor, igni admovetur". Apréciese que, como en las prácticas judiciales de tortura, el hablante no coincide con el verdugo: éste es impersonal; cualquiera puede acercar fuego a la cera. Cualquiera, también un instrumento (mecánica sustitución ventajosa del esclavo aristotélico). Los verbos en que Descartes narra la "purificación" de la cera aluden explicitamente a la tortura, y han sido "dulcificados" en la traducción francesa: saporis reliquiae purgantur, odor expirat, color mutatur, figura tollitur. "Purga", "expiración", "mutación" (es decir: metamorfosis violenta), "desaparición". ¿Qué es lo que resta? Ni siquiera el tacto, el sentido básico lucreciano, permanece: vir tangi potest. Y naturalmente, muere también todo sonido, toda respuesta "interior": nec jam, si pulses, emittet sonum. Ya no hay cosa. Sólo un objeto.

$Y$ sin embargo, Descartes se atreve a preguntar retóricamente si "eso" sigue siendo eadem cera, para responder al punto que nadie puede negar tal cosa. Lo que se ha "perdido" es justamente la confusión entre cosa y "yo", ejemplificada por los sentidos. Se ha perdido la frontera. Todo cuanto venia sometido a un rubro sensorial desaparece: remanet cera. Asi que lo que permanece es cera, en general, no esta cera. Queda "nihil aliud quam extensum quid, flexibile, mutabile." Puras relaciones, no ya a la mano ni a la vista, sino predispuestas a cualquier tipo de operacion de medida. Aqui no hay, contra las apariencias, nada exterior separado (la cosa, descansando en sí misma) ni interior secreto (el "yo", engolfado en la pura contemplación de sí: o sea, engolfado en nada). Lo que hay es la abstracta separación misma: la operación, repetible al infinito por cualquiera y en cualquier tiempo y lugar. Es como si la superficie de contacto, el límite o piel osmótica entre el hombre y las cosas, se hubiera independizado de ambos y flotara, exánime, en el reino de la pura matemática. Lo que resta es el juego inacabable del medir y el ser medido, a partir de una unidad fijada arbitrariamente. Ahora es ya todo claro y distinto. Todo, menos los "originales" reprimidos y el mismisimo "yo" represor. Ambos, separados, secretos. En el experimento (que no experiencia) del morceall de cire transformado en "cera, en general", en "masa", se anuncia ya oscuramente el enigma de la kantiana conjunción a tergo de la cosa en si y el "Yo, o Tú, o Ello (la Cosa, que piensa)". El mundo, convertido en superficie y pantalla, sigue apuntando a los miembros amputados, castrados: dos fondos que el idealismo intentará reunir en vano, para despenarse en el Abgrund del romanticismo. Detrás de la lógica y la industria se agazapa, pro-ducido por esas mismas instancias, lo Místico: que, a pesar de todo, el Mundo sea. Es el ansia de luz, el anhelo de conciencia pública lo que ha engendrado la oscuridad tenebrosa y el inconsciente. Der König Oedipus hatte vielleicht ein Auge zuviel.

Que el propio Descartes entreveía esta secreción de secretos a partir de la torturante "purificación" del hombre y las cosas, convertidos racionalmente en res cogitans (múltiple, a pesar de su apariencia de unidad) y res exrensa (única, a pesar de su apariencia de multiplicidad), lo prueban sus improbos esfuerzos por salvar al composinum, al synolon: ahora ya no propio de las cosas, sino justamente del "yo". $\Lambda \mathrm{l}$ fin, el problema de los cuerpos exteriores era mucho más fácil de resolver que el del propio cuerpo. Al fin, las sensaciones y percepciones son enganosas, pero sometidas al básanos, a la "piedra de toque" de la claridad y la distinción, no dejan de decir su verdad, o mejor: la verdad del Amo, al igual que en la antigua Grecia se torturaba el cuerpo del esclavo para ver si su dueño era culpable o inocente en los pleitos: al acercar al cuerpo el fuego, el esclavo dejaba de ser instrumentum vocale para convertirse, como la cera cartesiana, 
en instrumentum mutum, en purisimo lugar de la verdad, ya que lo que hablaba a través de su torturada garganta (dedicada de suyo a proferir mentiras) era la verdad del Amo, la verdad que éste pretendia esconder: "es esclavo — dice Aristóteles- por naturaleza el que puede depender de otro (por eso, precisamente, es de otro) y el que participa de la razón en tal grado como para percibirla, pero no para poseerla (hó koinonón lógou tosoütou hóson aisthánesthai allà mè échein)".9 Lo que ha hecho el "técnico" Descartes no ha sido sino la "traducción" industriosa del cuerpo del esclavo en la res extensa, la cual, muy cristianamente, participa desde luego del Lógos (pues que es criatura y ha quedado revestida de la formositas, de la hermosura lógica del Creador) pero no lo posee. Cuando las cosas se pliegan (a través de la experimentación) a la medida, ya no son necesarios esclavos, sino máquinas automatizadas. Lo que de las cosas de la perdida "experiencia" tradicional queda ya no tiene que ver con la phantasia, es decir, con cse lazo de unión entre lo sensible y lo inteligible al cual se dirigia el hombre mediante la reductio ad phantasmata. Por el contrario, ahora se abre el campo de la fantasia, de las puras alucinaciones de una mente separada, añorante de la vieja confusión, empeñada en estar en contacto directo con las cosas y a la vez en tener un mundo propio e intimo, no público. Quien tras Descartes se "reduce a los fantasmas" está loco y debe ser intemado en una institución que, a su vez, experimente con sus desvarios hasta lograr convertirlos, en lo posible, en manifestaciones bien medidas y archivadas de un continente ahora hundido: el inconsciente, nuestra prehistoria mental. Lo que nuestro filósofo ha descubierto quizá sans le savoir no es la subjetividad absoluta, a menos que por tal se entienda el vicjo etymon: ab-solutum, "suelto", desligado de toda realidad, una pura cláusula lógica, ni tampoco ha convertido el ser de lo ente en pura objetividad. Su descubrimiento es más pavoroso, y más superficial. Descartes ha descubierto la superficie, el campo de juego de las medidas que parcelan con sus análisis toda supuesta independencia sustancial: queda el campo de juego, la coordinatio rerum creatarum, la NaturalezaMáquina, flexible y móvil, reflejo de si misma o mejor; continuo desplazamiento y negación de si misma, juego de espejos matematizados: semiótica desligada de toda semántica. Desde esta perspectiva, bien podria decirse que la atribución de "realidad psiquica" a la bona mens cartesiana, el intento de crear un "mundo interior" desde la nueva ciencia de la psicologia no es sino una salida desespcrada ante la neutralidad ontológica sancionada por Descartes.

Al fin, percepciones y sensaciones son susceptibles — como vimos en el caso de la cerade ser reconducidas a esa verdad neutra. Objetos de ilusión, pues que confunden (ay cómo podrian no hacerlo?) nuestras percepciones con las cualidades de objetos, participan del primer y fundamental error de todo conocimiento. Si la regula generalis reza: "illud omne csse verum, quod valde clare \& distincte percipio", entonces el error común consisten que mis ideas, procedentes de las cosas exıra me: "omnino similes erant" a dichas cosas. ${ }^{10}$ Es decir, acaba por confundirse asi el signo con el referente. De manera análoga, las sensaciones son localizadas en la parte del cuerpo afectado, por la ignorancia de que el alma no siente en tanto que está en cada miembro del cuerpo, sino sólo en cuanto que está en el cerebro, como prueba el dolor "sentido"ll en un miembro amputado. Asi que sensaciones y percepciones participan de un doble error, tanto respecto a su atribución (nuestro cuerpo, un objeto exterior) como a su semejanza y adecuación con su objeto. Sólo que ese error apunta a un problema mucho mayor: seguramente, al único problema serio, para Descartes. Si tal sentimos o percibimos, ello se debe a la

\footnotetext{
9 Politica I, $5 ; 1254 \mathrm{~b} 22 \mathrm{~s}$

10 Med. III; A.T. VII, 35.

J Cf. Pr. IV, \$ 196.
} 
compenetración reciproca, vivida, entre nuestro cuerpo y nuestra alma: a la intimidad de la permixtio de ambos.

En la carta a Isabel de Bohemia de 28 de junio de 1643,12 Descartes afirma que hay tres nociones primitivas, esto es, irreductibles e incomparables: la del alma, la del cuerpo, y la de la unión entre alma y cuerpo. La primera es accesible mediante pensées métaplysiques, a los cuales hay que dedicar algunas horas al año, mediante el ejercicio del entendimiento puro (dada la dificultad de los principios en los que descansan tales pensamientos, Descartes señala a Isabel que basta con pensar en ellos "una vez en la vida"); la segunda se explicita mediante el conocimiento de las matemáticas, en las que se ejercita la imaginación bajo la guia de! entendimiento, mediante la consideración de figuras y movimientos; a tales pensamientos hibridos (prefiguración de los juicios sintéticos kantianos) pueden dedicarse algunas horas al dia; por fin, a la unión sólo oscuramente se llega por el entendimiento, aun ayudado por la imaginación, mientras que los sentidos se las han perfectamente con tales conocimientos confusos. Aquí, el pensamiento (aun ayudado por la imaginación) es más bien un estorbo; se accede a tales vivencias (dicho sea anacrónicamente) "en usant seulement de la vie et des conversations ordinaires". Podriamos pensar, siguiendo la progresión, que Descartes dedicaría todo el tiempo restante - o sea, casi todo el tiempo- a este tipo de confusiones (en realidad, es como si la occulorum concupiscentia agustiniana se hubiera extendido al campo entero de lo sensible: el reino de los monstruos y la ilusión). Al contrario, afirma que el resto de su tiempo lo emplea en el relajamiento de los sentidos y en el reposo del espiritu (en una palabra: en un suerio sin sueîos). Mejor no conocer nada que conocer confusamente. ¿lor qué? En la noción - tan primitiva como naturalmente ilusoria - de la unión del alma y el cuerpo anida una contradicción irresoluble. El cspiritu no debería concebir —distintamente y al mismo tiempo- la diferencia "sustancial" entre alma y cuerpo y la unión de ambos, pues ello seria concebirlos como una sola cosa y a la vez como dos. Y sin embargo, esto es lo que sucede de hecho. El "yo" cartesiano en poco se parece al "piloto" o "auriga" platónico: el cuerpo propio tiene una realidad autónoma, separada. Es un instrumentum, ciertamente. Pero, como la naturaleza de Bacon, ese instrumento sólo puede ser (parcialmente) dominado si previamente se le obedece, es decir, si se reconocen las leyes en las que se basa, lo cual implica, para empezar, que su anatomía debe ser cuidadosamente deslindada de la correspondiente al alma. Empresa casi desesperada, dado que el cuerpo parece "arctissime esse conjunctum \& quasi permixtum [con el esprit], adeo it untm quid cum illo componat." 13 Las sensaciones surgen justamente de esa permixtio mentis cunt corpore. Es más, el propio Descartes llega a oscilar respecto al estatuto de ese aparentemente indisoluble compositum, al hablar a renglón seguido de: "meum corpus, sive potius me totum". ¡ Yo soy el compuesto, no un "yo" separado! Por esa ilusión intima (ver una sustancia donde hay dos, y contrarias), la vida nos es amable y dulce. ¿Por qué es asi? El error inicial consiste en creer que el orden del mundo es semejante al orden de nuestros deseos y temores (o dicho freudianamente: creer que el principio del placer $y$ el de realidad son semejantes), y que las cosas están hechas para nosotros. Las razones aducidas por Descartes para explicar tal error liminar nos llevarán ahora a aguas más profundas: alli donde el cuerpo cartesiano dice sus verdades, torturándose el filósofo a si mismo como el heautentimorouménos de Terencio.

12 Correspondance avec Elisabeth. Flamnarion. Paris 1989, pp. 73-76. Las citas ulteriores se refieren a este escrito.

13 Med. VI; A.T. VII, 81. 
La raiz del error está en las pasiones: el modo más insidioso y casi inescrutable de penetración del cuerpo en el alma. ${ }^{14} \mathrm{Al}$ fin, percepciones y sensaciones eran oscuramente sinceras: apuntaban a cuerpos. Pero la pasión es toda ella de naturaleza ilusoria, ya que, siendo su causa corporal, se hace sentir como si fuera producida por el alma, es decir: se presenta como un pensamiento. ${ }^{15}$ En clara metonimia, el espíritu toma como causa propia lo que es un efecto del desvario de los espiritus animales obrando sobre la glándula pineal, en función de una conjunción súbita e involuntaria entre una impresión vívida, surgida una vez por la percepción de un objeto extraño y terrible, y otra provocada por una nueva impresión intensa, de modo que literalmente los espiritus animales deliran, esto es: salen de su surco natural y se enderezan del corazón al cerebro, excitando en el alma una pasión. Todo ello sucede tan rápidamente que el espiritu toma esa conjunción - mediada por un descarrio - como si fuera una sola operación. Esa confusión primordial no puede curarse racionalmente, sino mediante astucias e industrias (anuncio de la hegeliana "astucia de la razón"), temperando unas pasiones con otras. No interesa el mecanismo minuciosamente descrito por Descartes. Sí en cambio es importante atender al origen de la pasión. En la infancia, $\mathrm{e}$ incluso más acá de ésta, en la vida intrauterina del feto, el cuerpo aún no formado del todo, imperfecto, hace que el alma se entregue por entero a los órganos corporales, impidiendo toda abstención, toda suspensio judicii y aun toda atención a otra cosa que no sea la supervivencia del cuerpo. Litcralmente, en esta época, anterior al tiempo y al lenguaje, en esta verdadera prehistoria del alma (y por ende, del cuerpo) no existe todavia "Yo" ni "No-Yo", sino pura confusión original: algo asi como la uralte lenvirrung holderliniana, temida y sin embargo anhelada por los mismos dioses. Las marcas, los surcos trazados en el cerebro por las afecciones de la infancia acompañan al cuerpo durante toda su vida ("carácter" significa en griego "marca, trazo").

Sólo en el cuerpo formado, adulto, es posible encontrar la suficiente tranquilidad de espíritu como para que éste pueda vagar fuera de los sentidos, e incluso - parcialmente- fuera de esas marcas originarias. Sólo entonces es posible hablar con sentido, cuando la glándula pineal está abierta en las dos direcciones. Pero esas marcas son en definitiva irreductibles. Son ellas las que explican la aparente diferencia entre inteligencias y la diversa amplitud de la memoria. En todo caso, la memoria nunca puede ser, por principio, total: el alma no puede coincidir enteramente con su pasado porque la prehistoria de éste permanece en el olvido de la infancia, cuando aún no es posible hablar. Los sucnos y los desarreglos mentales no son en este sentido sino un regreso a la infancia: un desvario de los espiritus animales, que siguen, incontrolados, las huellas antiguas y olvidadas. ${ }^{16}$ Es más; al igual que la kantiana "ilusión trascendental", estos verdaderos pre-juicios seguiran inexorablemente orientando nuestros juicios, haciéndonos caer en el error, aun después de haber sido descubierta su falsedad: como un lenguaje falaz, anterior al lenguaje del cuerpo adulto, al lenguaje del logos, esos prejuicios están inscritos en

I4 Sobre este tema, véase el extraordinario estudio de F. Azouvi, Le róle du corps che: Descartes. REVUE DE METAPHYSIQUE ET DE MORALE 1 (1978) 1-23. Agradezco a Angel Gabilondo su gentileza al haberme proporcionado este importante texto. Sobre el tema de la infancia y la experiencia puede consultarse también Giorgio Agamben, Infanzia e ssoria. Einaudi. Turin 19782, pp. 3-62.

15 Correspondance. Carta de 6 de octubre de 1645 (ed. cit., p. 142 s.): "on peut généralement nommer passions toutes les pensées qui sont ainsi excitées en l'áme sans le concours de sa volonté (et par conséquent, sans aucune action qui vienne d'elle), par les seules impressions qui sont dans le cerveau, car tout ce qui n'est point action est passion. Mais on restreint ordinairement ce nom aux pensḱes qui sont causćes par quelque particulière agitation des esprits....Ainsi il ne reste que les pensées qui viennent de quelque particulière agitation des esprits, et dont on sent les effets comme en l'âme iname, qui soient proprement nommés des passions."

16 Les passions de l'ane [Pas.]. a. 21; Vrin. Parts 1966, p. 82. 
nuestro cuerpo, bajo forma de habirudes. ${ }^{17}$ Tendriamos que haber nacido adultos y duenos del lenguaje consciente, como Adán, para evitar esa falacia y poder poner con razón nombre a las cosas. Tendriamos, tambièn, que morir para poder prestar toda nuestra atención a las ideas del espíritu, no a las de la carne. De alguna manera, la filosofia cartesiana intenta esta verdadera praeparatio mortis, en lejano eco secularizado de aquellas famosas palabras atribuidas a San Pablo:

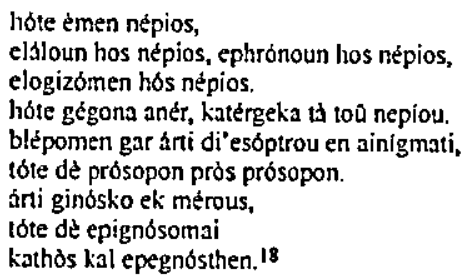

Sólo que en el tratamiento cartesiano de las pasiones anida una sospecha, impensable en el optimismo - pese a todo- paulino: la sospecha de que nunca, ni en un supuesto estado anterior a la permirtio, ni tras la muerte, podremos percibir las razones, las "verdades" del cuerpo. Todo cuanto se halla en el alma es en definitiva susceptible de reconocimiento: basta con prestar una atención máxima a ello, desligándose en lo posible gracias a la colaboración de un cuerpo sano (verdadero pharmakón del alma) que, como una oralidad transparente, debiera dejar que se leyera a su través las ideas innatas. Pero el cuerpo es un verdadero lenguaje (es decir: no dice toda la verdad): en él están inscritas trazas que ninguna atención espiritual podrá obviar, y menos borrar, sino sólo, humildemente, reconocer. Ninguna abduccion es aquí posible. Según la famosa confesión de Descartes a Chanut: "lorsque nous sommes portés à aimer quelqu'un sans que nous sachions la cause, nous pouvons croire que cela vient de ce qu'il y a quelque chose en lui de semblable à ce qui a été dans un autre objet que nous avions aimé auparavant, encore que nous ne sachons pas ce que c'est." 19 Y aqui no nos vale el consuelo del psicoanálisis: la metamorfosis inevitable de un movimiento en una cualidad no algo ni consciente ni inconsciente (lo último equivaldría a decir que contenidos de pensamiento son imperceptibles, lo cual es contradictorio). La mente está ya de siempre formada, en estado "adulto", por asi decir. Es el cuerpo quien restringe (o al contrario, posibilita, su actuación). En un sentido fuerte, habria que decir que, ontogenéticamente hablando, el cuerpo es anterior al reconocimiento de la mente por si misma. El cuerpo ha vencido siempre, ya de antemano, al cogito. Nada más obvio y conforme a los principios cartesianos, por lo demás. Baste recordar que el cogiso se descubre a si mismo cuando cae en la cuenta de que es él quien se equivoca, y de que no puede por menos de equivocarse, esto es, en el fondo: de ser apasionado.

Toda pasión es, en este sentido, un recuerdo corporal, una marca de la infancia. Y paradójicamente, esta ilusión irreductible que es la pasión no es nada falso, si por tal queremos decir que esconde una realidad accesible a la mente. Podemos analizar los mecanismos

$17 \mathrm{Cr}$. Pr: I, $\$ \$ 66-67$.

18 I. Cor: 13, 13-11: "Cuando yo era niño hablaba como niî̀o, pensaba como nino, razonaba como niño; cuando llegué a ser liombre dijé por inútiles las cosas de nino. Alora vemos por un espejo y confusamente, entonces veremos cara a cara. Al presente conozco sólo en parte, entonces conoceré por entero, y tal como soy conocido."

19 Carta de 6 de junio de 1647. A.T. V. 57. 
de las pasiones, atender a su química. Pero nunca estará en nuestra mano conocer las "verdades) del cuerpo cartesiano. Si creemos estar alegres, realmente lo estamos, aunque no sepamos concretamente por qué. Creer amar es ya eo ipso amar. Siempre seguiremos siendo, en el fondo, niños.

Nuestro cuerpo es un genio maligno mucho más poderoso y esquivo que el soñado por Descartes. De ahi que debamos conformarnos con un usage des passions moderado y prudente, pero nunca intentar erradicarlas, como creian - desvariando apasionadamente, a su vez- los sabios estoicos. Debemos aprender más bien a sacar todo el goce posible de ellas evitando los excesos unilaterales, controlando ese combate incesante que se da en el cruce de un cuerpo literalmente "prehistórico" y un alma que sólo puede controlar el lado "histórico" de su cuerpo. ${ }^{20}$ Toda pasión es antigua. Toda pasión es nativa: es la ilusión -condena y dulzura a la vez- de un nacimiento al que jamás asistimos, porque: "l'âme d'un enfant n'a jamais de conception pure, mais seulement des sensations confuses." 21

Y lo mismo ocurrirá con la muerte. Esta "n'arrive jamais par la faute de l'åme, mais seulement parce que quelcune des principales parties du corps se corrompt".22 De ahi el terror suscitado por la imagen de nuestra propia muerte, a partir de la contemplación de la muerte de los demás, conectada con la sensación de nuestra decadencia corporal. Sólo que, ¿no debería más bien regocijarse el alma, ya por adelantado, de esa futura liberación del cuerpo, cuando pueda dedicarse por si sola a las puras emociones intelectuales? ¿Se trata tan sólo de la ilusión de la pasión, o de la verdad de un abismo, entrevista por el analítico Descartes? Si es cierto que la irrupción de la vida hace que toda el alma quede como "offusquée du corps", ${ }^{23}$ si es cierto que la unión de alma y cuerpo está al servicio de la vida, al servicio de esa conjunción de movimientos y fuego cordial, en vez de estar al servicio de la verdad, ¿por qué la aflicción? ¿Puede incluso un Descartes añorar un alma desligada, desembarazada del cuerpo, embebida en sus solas percepciones, desatenta incluso al estudio de la naturaleza de las cosas exteriores, en vez de poner en el uso de las pasiones "toda la dulzura y felicidad de esta vida"24? ¿Por qué la verdad, reservada al solo espiritu, es vencida una y otra vez por la noción primitiva de la unión, de la vida? Y si Dios, como vimos al principio, coincide con el ordo naturae, ¿por qué la naturaleza nos endereza a la conservación del cuerpo - sin la cual, por lo demás, jamás accederíamos al cogito- en lugar de empujarnos a prescindir de aquél? Bien puede ser cierto que nuestro destino último sea el de amar a Dios y admirar y adorar: "immensi hujus luminis pulchritudinem", 25 ya que, según Descartes, la admiración es la única pasión no corporal, ya que no viene suscitada por movimientos desordenados de los espiritus animales, sino por la aparición de un objeto grandioso, antes de saber si nos es conveniente o nocivo. ${ }^{26}$ Pero esta primera "pasión" tiene todas las trazas de haber sido introducida ad hoc, para contrarrestar a todas las demás, ya que no entra en abosoluto en la definición común, dedicada por entero a lo mecánico y corporal, y su influjo involuntario en el alma.

Bien puede ser verdad, también, que aunque la pasión sea dulce y seductora, sólo el contento que proporciona el estar en posesión de la verdad es tan inmortal como la verdad

${ }^{20}$ Cf. Pas. a. 211, 212 (ed. cit., p. 215-218).

21 Carta a Arnauld de 4 de junio de 1648. A.T. V, 192.

22 Pas. a. 6 (ed.cit. p. 68 s.).

${ }^{23} \operatorname{Pr} 1, \$ 71$.

24 Carta a Silhon, marzo o abril de $1648 ; \mathrm{V}, 135$.

25 Aled. III; A.T. VII, 52.

26 Cf. Pas. a. 53 (ed.cit., p. 108 s.). 
misma, ${ }^{27}$ de modo que: "même sans les enseignements de la foi, la seule philosophie naturelle fait espérer à notre âme un état plus heureux, après la mort, que celui où elle est à présent."28

Pero, ¿cómo sabremos que este anhelo de liberación del cuerpo manifiesta una verdad o más aún: la única y altísima Verdad, en lugar de encubrir una pasión, una ilusión aún más fuerte e irreductible, a saber: la de liberamos de nuestra propia infancia y, por ende, de nuestra propia individualidad, si es cierto que las diferencias en inteligencin y memoria se deben solamente a las diferencias en la disposición corporal? ¿No lleva esa pasión por la Verdad a la indiferenciación plena, a una universalidad vacua, a la conversión en suma en un Dios gaseoso, más indeterminado aún que la materia cartesiana? Un conocer desinteresado y desilusionado: una vida suspendida como si ya se estuviera muerto, hacer de nuestra propia vida algo asi como una representación teatral de la que se conociera el entero texto, ¿supone de verdad un dominio racional de las posiones o un regreso al caos primigenio, antes de toda impresión? Si sabemos que soramos, ¿no se escapa acaso, incontenible, del alma fundida al cuerpo la voluntad suprema de Nietzsche: la de querer seguir soñando? ¿De dónde procede si no la nostalgia por la infancia perdida, anterior a todo Paraiso, anterior a todo nombre adánico?

Adán miraba el munda y no to conocia.

ni Lázaro,

ni yo.

\begin{abstract}
Adán abrió los ojos sin ninguna nostalgia, desasido del sueño original, amparándose a ciegas en la imagen y en la semejanza, y no entiende qué es, y ni siquiera sabe que está solo.

Su asombro es un jardin donde se precipita vertiginoso el universo; su dia como relámpago de tigres, su noche como defirio de su esquiva sombra. $Y$ no hay ningún deseo que le anuncie lo ajeno, la culpa y la calda.29
\end{abstract}

27 Correspondance. Carta a Isabel de 1 de septiembre de $16-45$ (ed.cit., p. 128)

28 ibid. p. 125.

29 Olga Orozco, "Miradas que no ven". En: Con esta boca, con esre mundo. Sudamericana. Buenos Aires $1995^{2}$, p. 79. 